\title{
Mapping the groundwater quality in Coimbatore city, India based on physico-chemical parameters
}

\author{
*Thangavelu, A \\ *Department of Environmental Science, Central University of Kerala, Kasaragod, India.
}

\begin{abstract}
Groundwater resources are explored in nature with the development of irrigation activities, industrialization, and urbanization etc. This study focuses on mapping the quality of groundwater using Geographical Information System (GIS) software. Thematic maps were generated from Survey of India (SOI) toposheets on 1:50,000 scale using ArcGIS. Physio-chemical parameters of the groundwater samples were collected at predetermined locations., spatial distribution maps of water quality parameters such as $\mathrm{pH}, E C$, TDS, Ca, Mg, Total Hardness (TH), Alkalinity, $\mathrm{Cl}_{2}, \mathrm{Na}, \mathrm{SO}_{4}{ }^{2-}$ and $\mathrm{K}$ of North Coimbatorewere prepared using ArcGIS 9.3. This provides the information about the existing quality of groundwater of the same area for the year2006. In this study, we have analyzed the samples of the same parameters discussed above and have estimated the risk prone levels in Coimbatore. This information can be further used to estimate the effect of water pollution in the regional level.

Keywords: GIS, Ground Water, Chemical Parameters, Mapping.
\end{abstract}

\section{Introduction}

Groundwater resources with the expansion of irrigation activities, industrialization and urbanization etc. [1]. This largest source of fresh water lying beneath the ground has become crucial for targeting potential zones, monitoring its quality high is required for domestic and irrigation needs the quality of water is tested for physical, chemical and biological parameters [2,3].Determining the quality of groundwater is crucial before its use. Water may be used for various purposes such as drinking, agricultural, recreational and industrial activities. GIS is identified to be a powerful tool for developing solutions for water resources problems, assessing water quality, determining water availability preventing flooding, understanding the natural environment and for managing water resources on a local or regional scale [4] the various databases. GIS has developed in integration and analysis of multi thematic layers in delineating ground water prospect and deficit zones $[5,6,7$, 8].

Decline of water quality in general, and groundwater in particular is of great concern [9]. Unchecked disposal of untreated municipal and industrial wastewater and excessive use of fertilizers and deteriorate the ground water. The groundwater of Coimbatore has been degraded due to rapid industrialization along with urbanization and agricultural activities in its surroundings areas [9]. All the industrial units consume large amount of water which, together with dissolved toxic substances (acids, base or toxic chemical compounds) after processing is discharged into nearby agricultural lands, ponds, open ditches, rivers, streams and open land. GIS advantages of integrating spatial, spectral and temporal availability of data covering large and inaccessible areas within short time it become a very handy tool in assessing, monitoring and conserving groundwater resources. The data provides quick and useful baseline information on the parameters controlling the quality of the water. However all the controlling parameters have rarely been studied together because of non-availability of data, integrating tools and modeling techniques. The systematic study of these factors leads to better delineation of prospective zones in an area which is then followed up on the ground through detailed hydrogeological investigation.

The present study to provide information regarding the spatial distribution of important physicalchemical parameters that affect water chemistry. Spatial distribution maps will also be produced using GIS for important physiochemical variables to understand groundwater quality and ecological status of the groundwater systems. The major aim of the study was to assess the physico-chemical parameters of drinking water sources.

\section{STUDY AREA}

The selected study area is north zone of Coimbatore city which lies between $76^{\circ} 81^{\prime \prime} \mathrm{N}$ to $77^{\circ} 23^{\prime \prime} \mathrm{N}$ and $10^{\circ} 83^{\prime} \mathrm{E}$ to $11^{\circ} 25^{\prime}$. Coimbatore city is one of the top 10 fastest growing cities of India. Coimbatore district has a population of about 34.73 Lakhs (Census in 2001). There are more than 25,000 small, medium, large scale industries and textile mills. It is located at the foothills of Western Ghats blessed with a wonderful climate and water. Coimbatore is $750 \mathrm{MSL}$ and average rainfall of $200 \mathrm{~mm}$ to $300 \mathrm{~mm}$, temperature ranging from moderate to medium. Coimbatore district is fed with water from Noyal, Siruvani, Bhavani and Amaravathi. 
Siruvani is the world second purest water body is the main source of water in the city. Coimbatore district is surrounded by Nilgris District, Erode District in Tamil Nadu and Palghat District in Kerala.

The North zone of Coimbatore consist of 22 wards comprises industrial residential, commercial areas. The data's of various water quality parameters of the groundwater samples collected in and around the North Coimbatore were Villankurichi, Poosaripalayam, Sanganur, VBG Layout, Tatabad, Dr.Radhakrish road, Rathinapuri, Krishnarayapuram, Bharathi colony, Peelamedu,Gp, State Busstand, Siddhapudur, Sanganur Main Road, Maniakarapalyam, CMC, Hope college, Ganapathi, LGB, Textool, PonniaGounder Street and Nallampalayam used for the digitization of the Map 1.

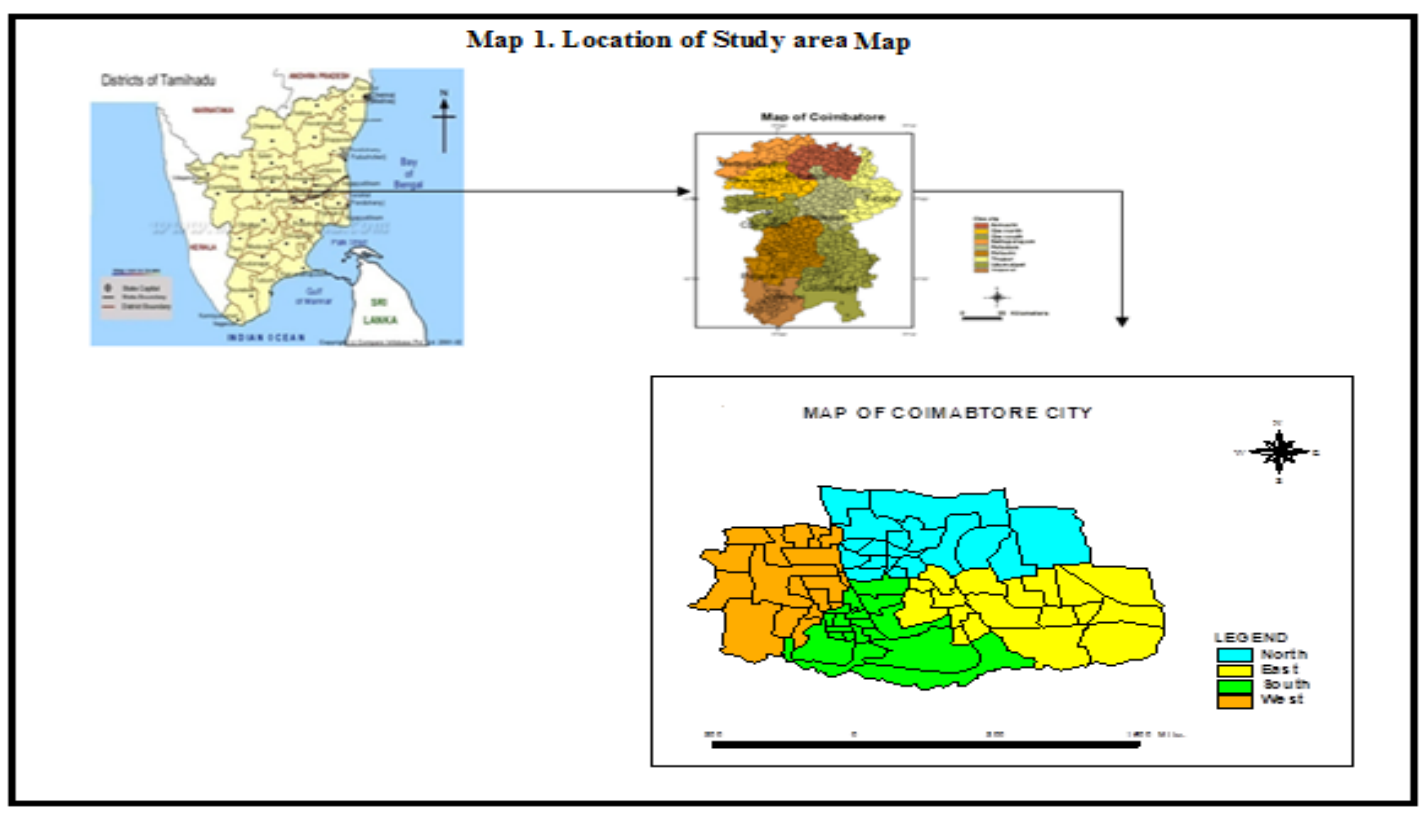

III. Methodology

The spatial co-ordinates of Coimbatore city area are indirectly worked out with the help of a Survey of India Toposheet (SOI) and a road map of Coimbatore to prepare the base map. After geo-referencing toposheet its coordinates are transferred to similar features on the land use map of Coimbatore to geo-reference it. The geo-referenced city map is Geo-coded and the geo-coding error is kept within 3 pixel range, with a pixel size of $20 \mathrm{~m} \times 20 \mathrm{~m}$. The geo-coded land-use map is digitized to obtain municipal \& ward boundaries. Subsequently, the north zone areas are isolated and a polygon histogram is constructed. The database on the properties of various parameters is generated. Then the thematic map on these water properties was generated by database analysis. The thematic maps were produced for $\mathrm{pH}$, electrical conductivity, total dissolved solids, total hardness, calcium hardness, magnesium hardness, alkalinity, chloride, sodium, potassium using the database. The results were compared with standard values recommended by World Health Organization WHO 2006[10]guidelines for drinking water quality.

\section{Results and Discussion}

Ground water quality modeling comprises the organization and presentation of knowledge about various parameters of the water, as they are classified and outlined on the maps. A well prepared map of the ground water parameters, based on the sound classification system is useful as the base for the different forms of interpretation. These data can be used for the development of agriculture, recharge sites, water management, irrigation purposes etc.

Based on the interpretation the potentialities and limitations of the ground water can be obtained and such information is used to construct database using GIS. The maps that obtained from the secondary data's are digitized and the attribute database is formed. Each polygon in the digitized map represents the various parameters that determine the quality of ground water.

The parameters that are digitized are $\mathrm{pH}$, TDS, Calcium, Magnesium and Total Hardness (TH), Electrical Conductivity (EC), Chloride, Alkalinity, Sodium, Potassium and Sulphate. Depth to groundwater ranges from shallow groundwater levels close to the ground surface to a depth of over $200 \mathrm{~m}$. The study areas were chosen in and around the North zone of Coimbatore and the secondary data for the water quality parameters for 24 study areas in and around north zone of Coimbatore city was collected and thematic map was produced in the table 1 and shown in the Map 2. 
Table 1: Shows the range of risk prone areas in the study area

\begin{tabular}{|c|c|c|c|c|c|c|c|c|c|c|c|}
\hline Study area & $\mathbf{p H}$ & EC & TDS & $\mathbf{C a}$ & Mg & TH & Alkalinity & $\mathrm{Cl}_{2}$ & $\mathbf{N a}$ & $\mathrm{SO}_{4}{ }^{2-}$ & $\mathbf{K}$ \\
\hline Villankurichi & $* *$ & $* * *$ & $* * *$ & $* * *$ & $* * *$ & $* * *$ & $* *$ & $* * *$ & $* * *$ & $* * *$ & $* * *$ \\
\hline Sanganur & $* *$ & $* *$ & $* * *$ & $* *$ & $*$ & $*$ & $* * *$ & $* *$ & $* *$ & $* *$ & $* *$ \\
\hline VBG Layout & $* *$ & $* * *$ & $* * *$ & $* * *$ & $* * *$ & $* * *$ & $* *$ & $* * *$ & $* * *$ & $* * *$ & $* * *$ \\
\hline Rathinapuri & $*$ & $* * *$ & $* * *$ & $* * *$ & $* * *$ & $* * *$ & $* *$ & $* * *$ & $* *$ & $* * *$ & $* *$ \\
\hline Krishnarayapuram & $* *$ & $* *$ & $* * *$ & $* *$ & $* * *$ & $* *$ & $* *$ & $* * *$ & $* * *$ & $* * *$ & $* *$ \\
\hline Bharathi colony & $* *$ & $*$ & $*$ & $* *$ & $* * *$ & $*$ & $* *$ & $* * *$ & $* * *$ & $*$ & $*$ \\
\hline Peelamedu & $* *$ & $*$ & $* *$ & $* * *$ & $* *$ & $* *$ & $* *$ & $* * *$ & $* *$ & $* *$ & $* *$ \\
\hline Siddhapudur & $* *$ & $* * *$ & $* * *$ & $* * *$ & $* * *$ & $* * *$ & $* *$ & $* * *$ & $* * *$ & $* * *$ & $* * *$ \\
\hline SanganurRoad & $* *$ & $* * *$ & $* * *$ & $* *$ & $* * *$ & $* *$ & $* *$ & $* * *$ & $* * *$ & $* * *$ & $* *$ \\
\hline Maniakarapalyam & $* *$ & $* * *$ & $* * *$ & $* *$ & $* *$ & * & * & * & $*$ & $* *$ & $* *$ \\
\hline $\mathrm{CMC}$ & $* *$ & $* * *$ & $* * *$ & $* * *$ & $* * *$ & $* * *$ & $* *$ & $* * *$ & $* * *$ & $* * *$ & $* * *$ \\
\hline Hope college & $* *$ & $* * *$ & $* * *$ & $* * *$ & $* * *$ & $* * *$ & $* *$ & $* * *$ & $* * *$ & $* * *$ & $* * *$ \\
\hline Ganapathi & $* *$ & $* *$ & $* * *$ & $* *$ & $* *$ & $*$ & $*$ & * & * & $* *$ & $* *$ \\
\hline LGB & $* *$ & $* *$ & $* *$ & $*$ & $* *$ & $* *$ & $* *$ & $*$ & $* *$ & $* *$ & $* *$ \\
\hline Textool & $* *$ & $*$ & $* *$ & $* * *$ & $*$ & $*$ & $*$ & $*$ & $*$ & $* * *$ & $* *$ \\
\hline
\end{tabular}

Key:

$*$ High incidences
** Moderate incidences
***Low incidences

1. pH

Generally, $\mathrm{pH}$ is the measure of acidity or alkalinity of water. It is one of the most importantoperational water quality parameters with the optimum $\mathrm{pH}$ required often being in the range of 7.0-8.5. The maximum permissible limit for $\mathrm{pH}$ for drinking water as given by the WHO is 9.2. The study clearly indicates that $\mathrm{pH}$ values range from 6.5 to 8. The samples from Rathinapuri, Sanganur main road and Nallampalayam shows very high $\mathrm{pH}$ while the rest shows moderate and low $\mathrm{pH}$ values. The $\mathrm{pH}$ range of the ground water samples in the study areas were tabulated as follows in Map 3. The values of $\mathrm{pH}$ show that all of the samples displayed a $\mathrm{pH}$ value within the maximum permissible limit.

\section{ELECTRICAL CONDUCTIVITY}

The EC is its measure of importance to salinity; which greatly affects the taste. Thus EC has a significant impact on determining the portability of water. The EC of water at $25^{\circ} \mathrm{C}$ is due to the presence of various dissolved salts. The EC varies with water sample and ranges between $469.2 \mu \mathrm{S} / \mathrm{cm}$ and $1173 \mu \mathrm{S} / \mathrm{cm}$ with an average of $800 \mu \mathrm{S} / \mathrm{cm}$. Knowing that the maximum limit of EC for drinking water is prescribed as $1,500 \mu \mathrm{S} / \mathrm{cm}$ at $25^{\circ} \mathrm{C}$, all the values are within the permissible limit. The study clearly indicates that EC values range from 0.5 to 6.The EC values of Bharathicolony, Peelamedu and Textool are high while the rest of the study areas show low and moderate values. The EC range of the ground water samples in the study areas were tabulated as follows in Map 4.

\section{TOTAL DISSOLVED SOLIDS}

TDS in water are represented by the weight of residue left when a water sample has been evaporated to dryness WHO (2006). TDS are compounds of inorganic salts (principally $\mathrm{Ca}, \mathrm{Mg}, \mathrm{K}, \mathrm{Na}$, Chloride and $\mathrm{SO}_{4}{ }^{2-}$ ) and of small amounts of organic matter that are dissolved in water. The TDS amount ranges between 50mg/l to $650 \mathrm{mg} / \mathrm{l}$ with an average of $367 \mathrm{mg} / \mathrm{l}$. The study clearly indicates that TDS values range from 0 to 2000 above.The TDS values of Bharathi colony is high while the rest of the study areas show low and moderate values. The TDS range of the ground water samples in the study areas were tabulated as follows in Map 5. 


\section{CALCIUM HARDNESS}

$\mathrm{Ca}$ is from natural sources like granitic terrain which contains large concentration of these elements $\mathrm{Ca}$ is within the permissible limits of $75 \mathrm{mg} / \mathrm{l}$ except one station where it is exceeding the permissible limit. $\mathrm{Ca}$ is ions of total hardness and hence they are interrelated. The study clearly indicates that $\mathrm{Ca}$ hardness is less than 75 to above 150.The Ca Hardness values of LGB are high when compared to the other study areas which show low and moderate values. The $\mathrm{Ca}$ range of the ground water samples in the study areas were tabulated as follows in Map 6.

\section{MAGNESIUM HARDNESS}

$\mathrm{Mg}$ is exceeding the permissible limit of 30mg/l in more than $75 \%$ of the sampling stations. The study clearly indicates that $\mathrm{Mg}$ hardness is less than 150 to less than 350.The Mg Hardness values of Sanganur, Bharathi colony, Textool are high when compared to the other study areas which show low and moderate values. The Mg range of the ground water samples in the study areas were tabulated as follows in Map 7.

\section{TOTAL HARDNESS}

$\mathrm{TH}$ is to be used for domestic, industrial or agricultural purposes. It is due to the presence of excess of $\mathrm{Ca}$ and $\mathrm{Mg}$. The carbonate and bicarbonate concentrations are useful to determine the temporary hardness and alkalinity. TH obtained shows that $25 \%$ of the samples are exceeding the permissible limit of $200 \mathrm{mg} / \mathrm{l}$ set by WHO (2008). The study clearly indicates that total hardness is less than 500 to less than 1600.The Total Hardness values of Poosaripalayam, Sanganur, Bharathi colony, Maniakarapalyam, Textool and Ganapathy are high when compared to the other study areas which show low and moderate values. The Total hardness range of the ground water samples in the study areas were tabulated as follows in Map 8.

\section{ALKALINITY}

Alkalinity values less than 75 milligrams per liter can change $\mathrm{pH}$ levels in water and make the water corrosive. Corrosive water can then lead to potentially harmful metals dissolving from the plumbing into the drinking water. The study clearly indicates that Chloride is less than 60 to above 100 . The Alkalinity values of Poosaripalayam, Ganapathy, Maniakarapalyam, Textool are high when compared to the other study areas which shows low and moderate values. The Alkalinity range of the ground water samples in the study areas were tabulated as follows in Map 9.

\section{CHLORIDE}

Chloride occurs naturally in all types of water. Chloride in natural water may results from agricultural activities, industries and chloride rich rocks. The results obtained shows that all the sampling stations are well within the permissible limit of $250 \mathrm{mg} / \mathrm{l}$ guided by WHO (2008) guidelines for drinking water quality. The study clearly indicates that Chloride is less than 260 to less than 800.The Chloride values of Poosaripalayam, Sanganur, Bharathi colony, Maniakarapalyam, LGB and Textool are high when compared to the other study areas which show low and moderate values. The Chloride range of the ground water samples in the study areas were tabulated as follows in Map 10.

\section{SODIUM}

$\mathrm{Na}$ is the most important minerals occurring naturally. The major source of both the cations may be weathering of rocks besides the sewage and industrial effluents. Their values of study area show that $\mathrm{Na}$ is well within the permissible limits. The study clearly indicates that $\mathrm{Na}$ is 1 to 360 . The $\mathrm{Na}$ values of Poosaripalayam, Sanganur, Bharathi colony, Maniakarapalyam, Textool are high when compared to the other study areas which show low and moderate values. The Total hardness range of the ground water samples in the study areas were tabulated as follows in Map 11.

\section{SULPHATE}

Sulphate is found in small quantities in ground water. Sulphate may come into groundwater by industrial or anthropogenic additions in the form of Sulphate fertilizers. The values from the study area are all within the permissible limit of $250 \mathrm{mg} / \mathrm{l}$ WHO (2008) for drinking water purpose. The study clearly indicates that Sulphate is less than 60 to less than 190. Sulphate values of Bharathi colony is high when compared to the other study areas which shows low and moderate values. The Sulphate range of the ground water samples in the study areas were tabulated as follows in Map 12.

\section{POTASSIUM}

$\mathrm{K}$ is the most important minerals occurring naturally. The major source of both the cations may be weathering of rocks besides the sewage and industrial effluents. Their values of study area show that $\mathrm{Na}$ is well 
within the permissible limits. The study clearly indicates that $\mathrm{K}$ is less than 16 to less than 46 . The Potassium values of Bharathi colony is high when compared to the other study areas which shows low and moderate values. The Total hardness range of the ground water samples in the study areas were tabulated as follows in Map 13.

\section{Conclusion}

Ground water is mostly used drinking water and irrigation purpose. The chemical characteristics of ground water are determined by the level of contribution from the geological sources and infiltration water from the surface sources. The chemical characteristics of ground water under natural conditions vary spatially as result of variation in the chemical characteristics of their contributing sources. Hence the knowledge about the water parameters is important to determine its quality.

Water quality is a critical factor in well-being of any area. The various parameters studied are within the permissible limits as per World Health Organization (WHO) and Indian Council of Medical Research (ICMR) norms for drinking water. In this situation any professional may need the water parameters data. This data is spatial in nature and they can be easily handled and analyzed using GIS. Distribution and diffusion of information is easier when the information is stored in digital form. GIS can be analyzed the data to get the desired information. Hence the advantage in the use of GIS in handling of ground water parameters data is proved in this task.

From this study the ranges of various parameters in the study areas in and around north zone of Coimbatore is estimated. The alarming rate of increase in some of the parameters in some study areas is observed. This would help in designing various strategies to bring them in control. The mapping of various water quality determine parameters of the selected study areas will be helpful for the conservation practices and also to minimize the ground water pollution potential due to the various environmental factors and this study shall illustrate the importance of spatial modelling and in solving the spatial problems encountered in the workplace. This will be beneficial to educators, students and GIS practitioners alike in determining the capabilities that are required in the public health sector.

The analysis of the results drawn at various stages of the work revealed that integration of GIS are effective tools for the preparation of various digital thematic layers and maps showingspatial distribution of various water quality parameters. Monitoring of pollution patterns and its trends with respect to urbanization is an important task for achieving sustainable management of groundwater [11]. An integrated GIS study proves to be an essential tool to evaluate and quantify the impacts of land use / land cover on ground water quality. Spatial distribution maps of various pollution parameters are used to demarcate the locational distribution of water pollutants in a comprehensive manner and help in suggesting groundwater pollution control.

\section{References}

[1]. Suvarna tikle1, Mohammad JawidSaboori and RushikeshSankpal (2012) Spatial Distribution of Ground water Quality in Some Selected parts of Pune city, Maharashtra, India using GIS, Vol. 7(2), 281-286 (2012)

[2]. Sargaonkar, A. and V. Deshpande (2003). Development of an overall index of pollution for surfacewater based on a general classification scheme in Indian context. Environmental Monitoring and Assessment, (89): 43-67.

[3]. Khan, F., T. Husain and A. Lumb (2003). Water quality valuation and trend analysis in selected watersheds of the Atlantic Region of Canada.Environmental Monitoring and Assessment, (88): 221-242.

[4]. Ferry, L.T., K. Akihiko and M.A. Mohammed Aslam, (2003). A Conceptual Database Design for Hydrology Using GIS.In the Proceedings of Asia Pacific in Association of Hydrology and Water Resources, Japan, Kyoto.

[5]. Carver S., (1991). Integrating multi-criteria evaluation with geographic information systems.International Journal Geographical Information Science 5, 321-339.

[6]. 6.Hoogendoorn, J.H., Van Der Linden, W.S., De Storet, C.B.M., (1993). The Importance of GIS in Regional Geohydrological Studies. In: Proc.International Conference on Application of Geographic Information System in Hydrology and Water Resource Management, Vienna, Austria, April 19-22, IAHS Pub. No.211. 375-383.

[7]. Rokade, V.M., Kundal, P., Joshi, A.K., (2007). Groundwater potential modeling through remote sensing and GIS: A case study from RajuraTaluka, Chandrapur District, Maharashtra. Jour. Geol. Soc. India, 69 (5), 943-948.

[8]. ThushanChandrasiriEkneligoda, HerbertHenkel., (2010). Interactive spatial analysis of lineaments.Computers\& Geosciences. 36, 1081-1090.

[9]. Qadir A, Malik RN, Hussain SZ (2008) Spatio-temporal variations in water quality of NullahAik-tributary of the river Chenab, Pakistan.Environmental Monitoring and Assessment, 140: 43-59.

[10]. WHO, Guidelines of drinking water quality Recommendation: the $3^{\text {rd }}$ edition. Geneva: World Health Organisation. 2 :( 2006).

[11]. Asadi, S.S., P. Vuppala and M. Anji Reddy, (2007). Remote Sensing and GIS Techniques for Evaluation of Groundwater Quality in Municipal Corporation of Hyderabad (Zone-V), India. Int. J. Environ. Res. Public Health, 4(1): 45-52.F. 
VI. Results Analysis
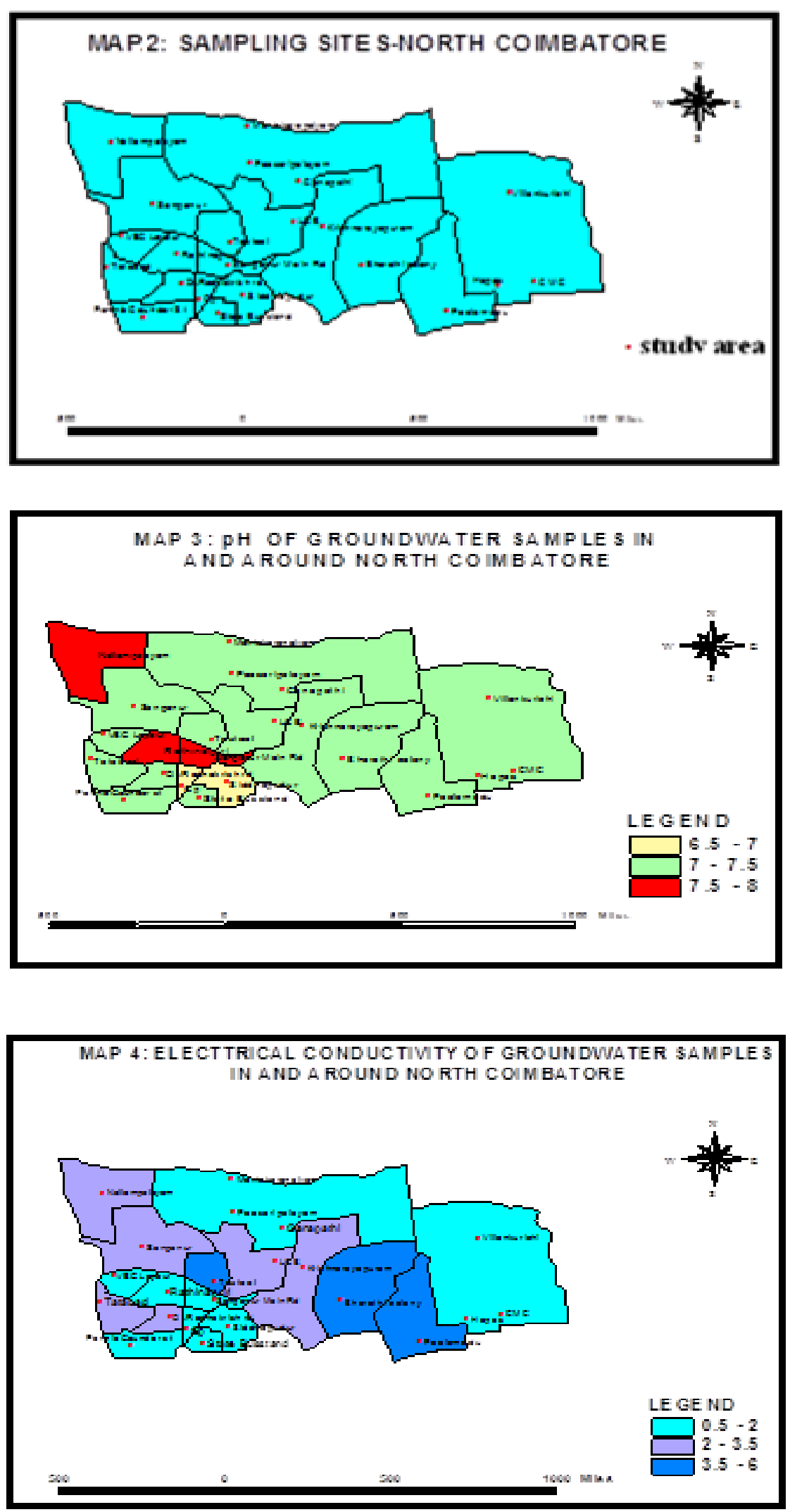

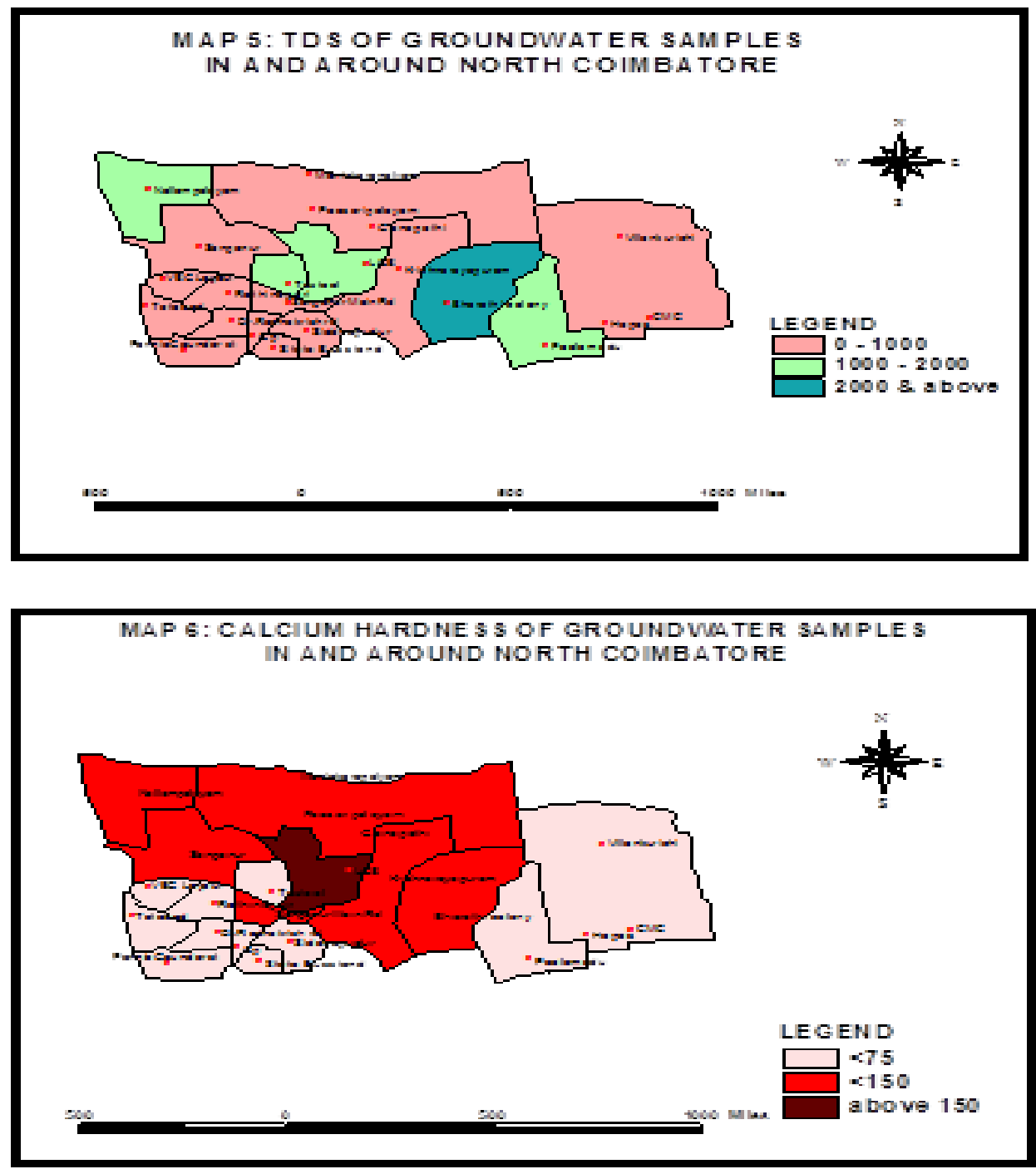

MAF T: MAQNESUM HARDNES OFGROUNDWATER IAMFLEล SAMDAROUND NOFTH COM BATORE
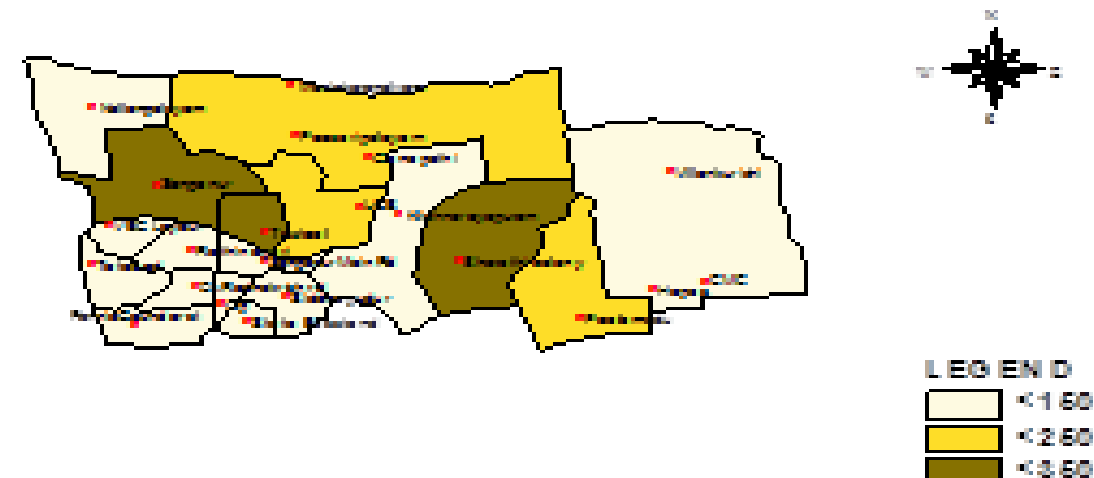

en 


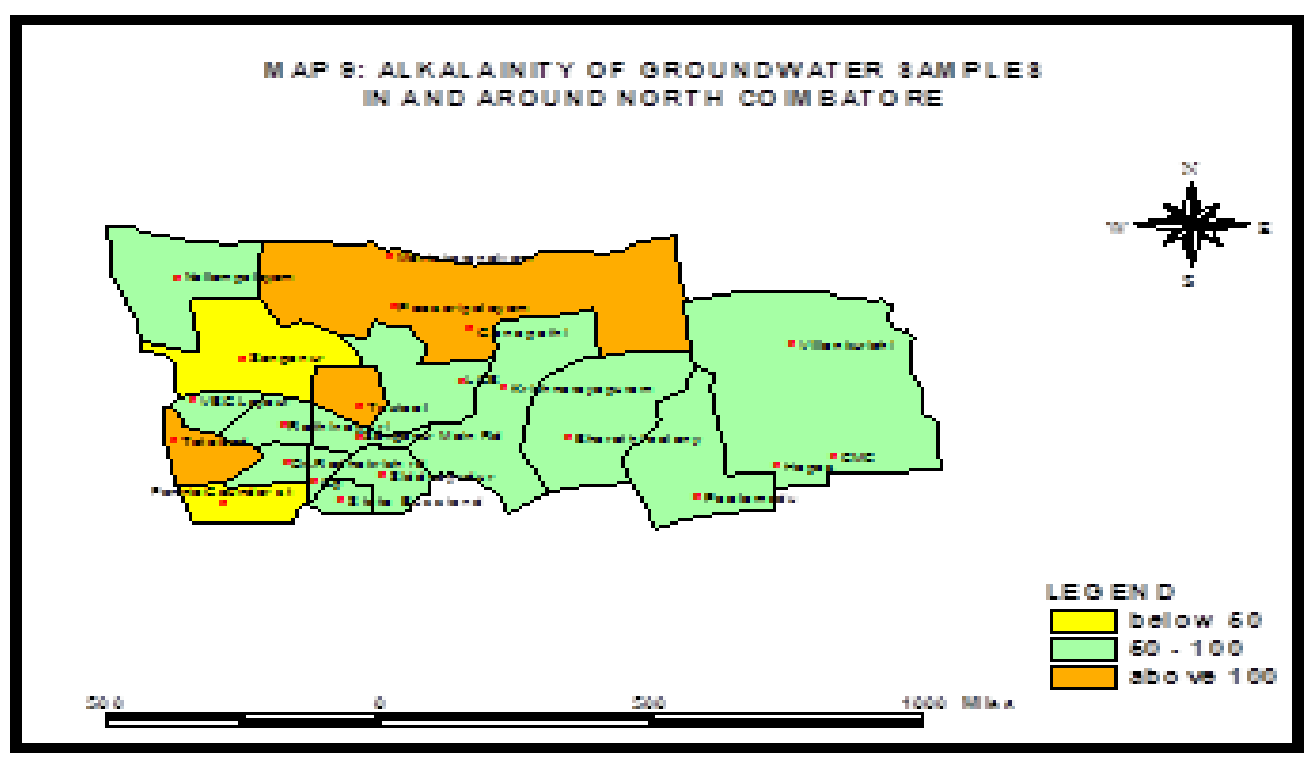

MAF 10: CHLOFIE OF QROUHDWATERE SAMFLE

HA AND AROUIND HORTH COMEATORE
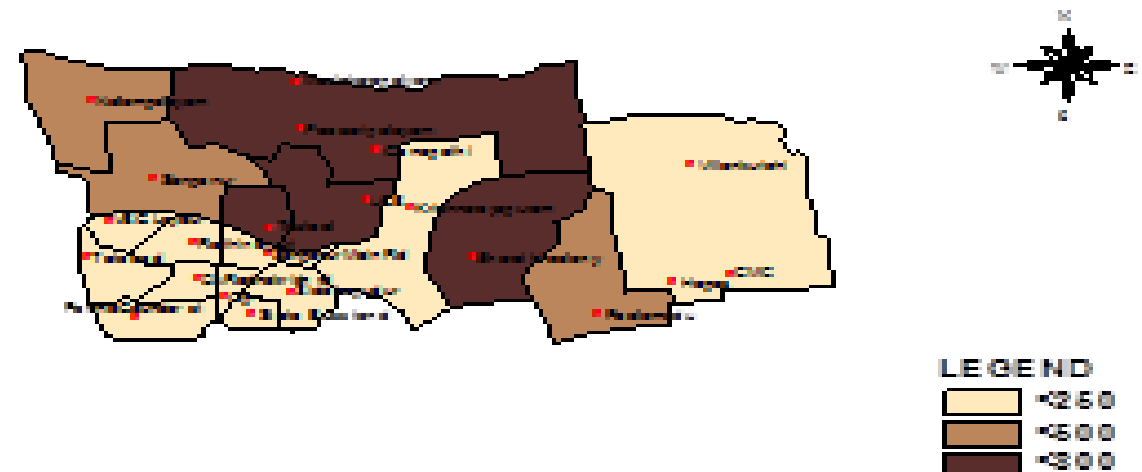

\section{불}

-20
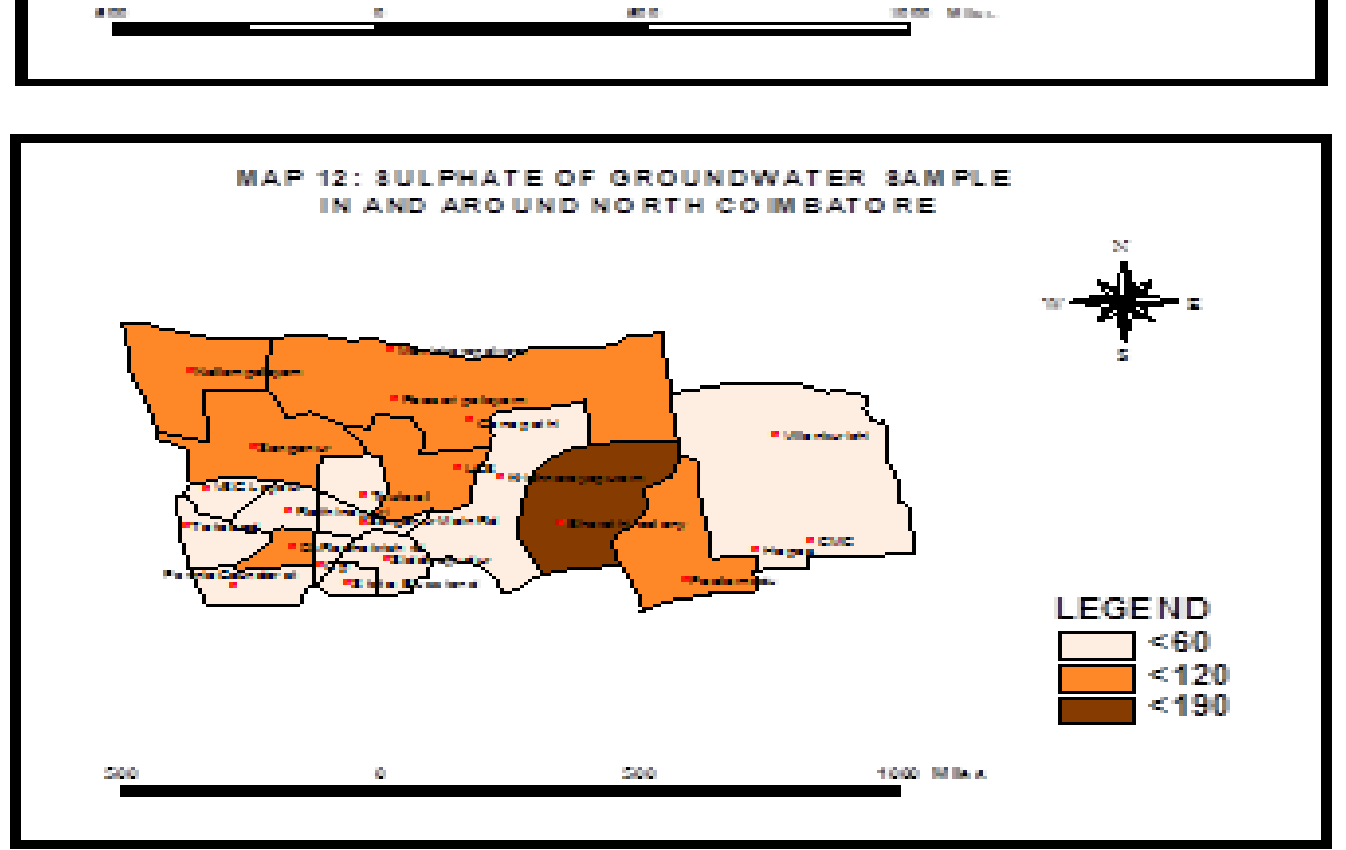

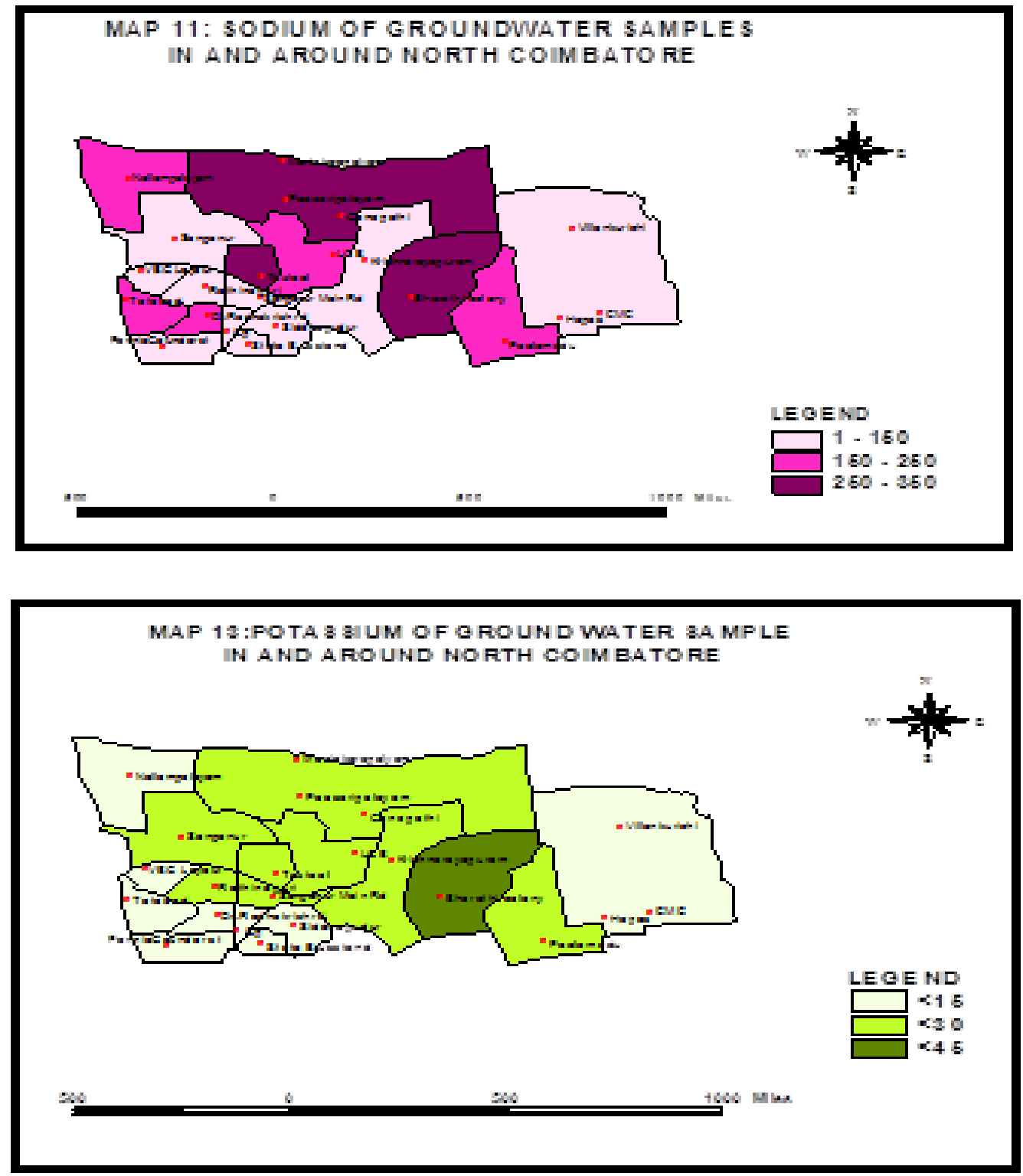